\title{
MÉTODOS DE SUPERAÇÃO DE DORMÊNCIA EM SEMENTES DE MAXIXE
}

\author{
Paula Michele da Silva Schmidt ${ }^{1}$, Ubirajara Russi Nunes ${ }^{2}$, Fernanda Alice Antonello \\ Londero Backes ${ }^{2}$, Pablo Reno da Silva Sangoi ${ }^{3}$, Lovane Klein Fagundes ${ }^{4}$, Tiéle Stuker \\ Fernandes $^{5}$, Joner Silveira Dalcin ${ }^{5}$
}

${ }^{1}$ Engenheira Agrônoma, Universidade Federal de Santa Maria - UFSM, Santa Maria, Rio Grande do Sul, Brasil.

${ }^{2}$ Docente da Universidade Federal de Santa Maria (Fitotecnia) - UFSM, Santa Maria, Rio Grande do Sul, Brasil.

${ }^{3}$ Graduando em Agronomia, Universidade Federal de Santa Maria - UFSM, Santa Maria, Rio Grande do Sul, Brasil.

${ }^{4}$ Doutora em Agronomia, Universidade Federal de Santa Maria - UFSM, Santa Maria, Rio Grande do Sul, Brasil.

${ }^{5}$ Doutoranda em Agronomia, Universidade Federal de Santa Maria - UFSM, Santa Maria, Rio Grande do Sul, Brasil.

RESUMO: Algumas espécies da família Cucurbitaceae apresentam dormência de sementes, inclusive o maxixe. Assim, o objetivo deste trabalho foi estudar métodos de superação de dormência em sementes de maxixe. As sementes foram submetidas aos seguintes tratamentos: $\mathrm{T} 1$ = Testemunha, $\mathrm{T} 2=$ Embebição por 3 dias em água destilada, $\mathrm{T} 3=$ Embebição por 4 dias em água destilada, T4 = Imersão em solução de $\mathrm{NaClO} 10 \%$ por 10 minutos, $\mathrm{T} 5$ = Imersão em solução de $\mathrm{NaClO} 10 \%$ por 48 horas, T6 = Imersão em solução de $\mathrm{NaClO} 10 \%$ por 10 minutos e secagem em temperatura ambiente por 48 horas, $\mathrm{T} 7=$ Imersão em solução de $\mathrm{NaClO} 10 \%$ por 10 minutos e secagem em estufa a $40^{\circ} \mathrm{C}$ por 48 horas, $\mathrm{T} 8=$ Imersão em solução de $\mathrm{NaClO} 10 \%$ por 10 minutos e secagem em temperatura ambiente por 72 horas, T9 = Escarificação química com $\mathrm{H}_{2} \mathrm{SO}_{4}$ por 1 minutos, $\mathrm{T} 10=$ Escarificação química com $\mathrm{H}_{2} \mathrm{SO}_{4}$ por 2 minutos, T11 = Escarificação mecânica com lixa por 10 segundos, T12 = Escarificação mecânica com lixa por 20 segundos. A avaliação dos tratamentos foi realizada pelos seguintes testes: germinação, primeira contagem da germinação, comprimento de raiz e parte aérea de plântula, massa seca de plântula e emergência de plântulas em areia, utilizando o delineamento inteiramente casualizado. A dormência das sementes de maxixe é superada com embebição por quatro dias em água destilada, imersão em solução de $\mathrm{NaClO} 10 \%$ por 10 minutos e secagem em temperatura ambiente por 48 horas e escarificação mecânica por 10 ou 20 segundos.

Palavras-chave: Cucumis anguria L. Germinação. Testes.

\section{DORMANCY OVERCOMING METHODS IN MAXIXE SEEDS}

ABSTRACT: Some Curcubitacea family species have dormant seeds, including the Gherkin. The objective of this work was to study methods of scarification in gherkin seed. Cultura Agronômica, Ilha Solteira, v.26, n.1, p.53-60, 2017 
Seeds were subjected to the following treatments: $\mathrm{T} 1=$ Witness, $\mathrm{T} 2=$ Soaking for 3 days in distilled water, T3 = Soaking for 4 days in distilled water, T4 = Immersion $\mathrm{NaClO} 10 \%$ solution for 10 minutes, T5 = immersion solution of $10 \% \mathrm{NaClO}$ for 48 hours immersion T6 $=10 \% \mathrm{NaClO}$ solution for 10 minutes and dried at room temperature for 48 hours, $\mathrm{T} 7=$ immersed in a solution of $10 \% \mathrm{NaClO}$ for 10 minutes and dried at $40^{\circ} \mathrm{C}$ for 48 hours , $\mathrm{T} 8=$ Immersion $\mathrm{NaClO} 10 \%$ solution for 10 minutes and drying at room temperature for 72 hours, $\mathrm{T} 9=$ chemical scarification with $\mathrm{H} 2 \mathrm{SO} 4$ for 1 minutes, $\mathrm{T} 10=$ chemical scarification with $\mathrm{H} 2 \mathrm{SO} 4$ for 2 minutes, T11 = mechanical scarification with sandpaper for 10 seconds T12 = Mechanical scarification with sandpaper for 20 seconds. The evaluation of treatments was performed by the following tests: germination, first count of germination, root length and shoot seedling, seedling dry matter and emergency sand in seedlings, using a completely randomized design. The gherkin seed dormancy is overcome by soaking for four days in distilled water, immersed in $10 \%$ solution of $\mathrm{NaClO}$ for 10 minutes and dried at room temperature for 48 hours and chiseling for 10 or 20 seconds.

Key words: Cucumis anguria L. Germination. Tests.

\section{INTRODUÇÃO}

O maxixe (Cucumis anguria L., Cucurbitaceae) é uma olerícola de origem africana e foi introduzida no Brasil por influência dos escravos. É uma espécie de clima quente, que apresenta rusticidade, suportando temperatura e pluviosidade elevada. Apesar da produção ser mais concentrada nas regiões norte, nordeste e centro-oeste do Brasil, e onde os frutos são mais apreciados, podem ser produzidos em clima subtropical como no Rio Grande do Sul, em períodos onde as temperaturas estejam mais elevadas (QUEIRÓZ, 1993).

É uma cultura que apresenta baixo desempenho produtivo, sendo sua propagação através de sementes. Porém, a comercialização de sementes é pouco significativa, quando comparadas a outras olerícolas, isso porque o cultivo é pouco tecnificado, e na maior parte subsistencial, e a diversidade genética do material cultivado, resultando na desuniformidade da produção de frutos e sementes (MEDEIROS et al., 2010).

Os requisitos básicos para a implantação de uma cultura, é que as sementes sejam providas de boa qualidade física, genética, fisiológica e sanitária (CARVALHO; NAKAGAWA, 2000). Pois o sucesso de uma produção agrícola inicia pela obtenção de sementes de boa qualidade, visto que plantas oriundas de sementes de baixa qualidade terão produção abaixo de seu potencial genético (ALBUQUERQUE et al., 2009).

Muitas sementes apresentam dificuldade de germinarem, mesmo diante de condições favoráveis de ambiente, isso não significa que elas apresentam um baixo potencial fisiológico, mas devido a fatores internos ou causas determinadas pela própria semente, que torna o embrião incapaz de reassumir nível suficiente de crescimento para a protrusão radicular, o que denomina-se, dormência (EGLEY, 1995). 
A dormência em sementes, por um lado, pode ser vista como uma forma de preservação da espécie vegetal, e por outro, como sendo um entrave para a rapidez na germinação, e uniformidade do estande de plantas. Conforme Marcos Filho (2005) existem várias causas de dormência, a mais encontrada é aquelas que se relacionam com a impermeabilidade do tegumento á água, a resistência mecânica do tegumento, a impermeabilidade do tegumento a trocas gasosas, e a ação de substâncias inibidoras.

Alguns trabalhos relatam métodos usados para a superação de dormência em sementes de espécies da família das Cucurbitaceae, como por exemplo, em sementes de Bucha (Luffa cylindrica Roemer), onde a escarificação mecânica com lixa e o corte do lado oposto ao do hilo foram os tratamentos com melhor germinação (MOREIRA et al., 2007). Já em sementes de melão de São Caetano (Momordica charantia L.) se obteve melhores resultados de germinação e velocidade de germinação, quando as sementes foram imersas em ácido sulfúrico $\left(\mathrm{H}_{2} \mathrm{SO}_{4}\right)$ concentrado por 3 minutos (PARREIRA et al., 2012). Dantas et al. (2003), em estudos com melancia, encontraram na escarificação mecânica com lixa, um dos métodos mais eficazes para a superação de dormência nessa espécie olerícola, já que a ruptura do tegumento por meio da escarificação, além de aumentar a permeabilidade a água e gases, pode promover aumento da sensibilidade à luz e a temperatura, atuando sobre o metabolismo das sementes (CARVALHO; NAKAGAWA, 2000).

Estudos para a superação de dormência em sementes de cucurbitáceas, principalmente com o melão, a melancia e abóboras, já vem sendo realizados a décadas (HAIM, 2007), no entanto são escassos os estudos com sementes de maxixe. As Regras para Análise de Sementes (BRASIL, 2009) padroniza o teste de germinação e primeira contagem de germinação (vigor) em maxixe, mas não faz nenhuma observação quanto aos métodos para superar a dormência. Diante do exposto, o objetivo deste trabalho foi comparar a eficiência de diferentes métodos de superação de dormência em sementes de maxixe, para a determinação da sua qualidade físiológica.

\section{MATERIAL E MÉTODOS}

O experimento foi conduzido no Laboratório Didático e de Pesquisa em Sementes da Universidade Federal de Santa Maria - UFSM, RS. Os frutos maduros, com exocarpo de coloração amarela, foram colhidos aleatoriamente de uma população de plantas no ano de 2013 na área experimental da UFSM. As sementes foram extraídas manualmente da polpa e lavadas em água corrente, e, em seguida, submetidas aos diversos tratamentos listados na Tabela 1.

A imersão das sementes em solução de $\mathrm{NaClO} 10 \%$ foi realizada em caixas de plástico, tipo gerbox, sem lavagem posterior das sementes. $\mathrm{Na}$ imersão em $\mathrm{H}_{2} \mathrm{SO}_{4}$ as sementes foram colocadas em Becker, revolvidas com um bastão de vidro visando uniformizar a ação abrasiva do ácido e, posteriormente, lavadas por 1 minuto em água

Cultura Agronômica, Ilha Solteira, v.26, n.1, p.53-60, 2017 
destilada. A escarificação mecânica foi realizada em escarificador elétrico de lixa utilizando-se lixa para madeira número 80.

Tabela 1. Tratamentos pré-germinativos aplicados para superação da dormência de sementes de maxixe. Santa Maria, RS, 2014.

Tratamentos pré-germinativos

T1 = Sem tratamento pré-germinativo (testemunha)

T2 = Embebição por 3 dias em água destilada

T3 = Embebição por 4 dias em água destilada

T4 = Imersão em solução de $\mathrm{NaClO} 10 \%$ por $10 \mathrm{~min}$

T5 = Imersão em solução de $\mathrm{NaClO} 10 \%$ por $48 \mathrm{~h}$

T6 = Imersão em solução de $\mathrm{NaClO} 10 \%$ por 10min e secagem em temperatura ambiente por $48 \mathrm{~h}$

$\mathrm{T} 7$ = Imersão em solução de $\mathrm{NaClO} 10 \%$ por 10 min e secagem em estufa a $40^{\circ} \mathrm{C}$ por $48 \mathrm{~h}$

T8 = Imersão em solução de $\mathrm{NaClO} 10 \%$ por 10 min e secagem em temperatura ambiente por $72 \mathrm{~h}$

T9 = Escarificação química com $\mathrm{H}_{2} \mathrm{SO}_{4}$ concentrado por 1 min

$\mathrm{T} 10$ = Escarificação química com $\mathrm{H}_{2} \mathrm{SO}_{4}$ concentrado por $2 \mathrm{~min}$

T11 = Escarificação mecânica com lixa por $10 \mathrm{seg}$

T12 = Escarificação mecânica com lixa por $20 \mathrm{seg}$

A avaliação dos efeitos dos tratamentos foi realizada pelos seguintes testes: Germinação: conduzido em BOD regulada a $32^{\circ} \mathrm{C}$, sob luz constante, com quatro repetições de 50 sementes para cada tratamento, sendo as contagens realizadas aos 4 dias (primeira contagem) e aos 8 dias (BRASIL, 2009). O teste foi conduzido em gerbox, sob duas folhas de papel filtro e umidade de 2,5 vezes o peso do papel seco, e os resultados expressos em percentagem de plântulas normais. - Comprimento da raiz primária e da parte aérea: realizado ao final do teste de germinação, obtendo-se o valor médio de 10 plântulas normais de cada repetição dos tratamentos, com o auxílio de uma régua graduada e os resultados expressos em centímetros (NAKAGAWA, 1999). - Massa seca: massa da matéria seca de 10 plântulas normais de cada repetição, colocadas em estufa a $65^{\circ} \mathrm{C}$ por 48 horas (NAKAGAWA, 1999). - Emergência de plântulas em areia: as sementes foram semeadas em bandejas plásticas com substrato de areia previamente lavada, esterilizada e peneirada utilizando-se 25 sementes em sulcos de $1 \mathrm{~cm}$ de profundidade, com quatro repetições para cada tratamento (BRASIL, 2009). A umidade do substrato foi mantida em $60 \%$ da capacidade de retenção de água, com irrigações frequentes e a $32^{\circ} \mathrm{C}$ em $\mathrm{BOD}$, sob luz constante, determinando-se o número final de plântulas emergidas em 8 dias após a semeadura. Este teste foi realizado apenas para os tratamentos T3, T6 e T11.

Foi utilizado o delineamento inteiramente casualizado e os dados submetidos à análise de variância. Os dados de germinação e primeira contagem da germinação foram

Cultura Agronômica, Ilha Solteira, v.26, n.1, p.53-60, 2017 
previamente transformados em arco-seno $\sqrt{\% / 100}$, para análise estatística. As comparações entre as médias foram feitas mediante a aplicação do teste de Scott-Knott ( $p>0,05)$.

\section{RESULTADOS E DISCUSSÃO}

Devido à baixa germinação observada na testemunha (T1), observou-se que as sementes possuíam algum tipo de dormência (Tabela 2). Esse fato foi confirmado com o aumento de germinação quando as sementes foram submetidas a alguns tratamentos para superação de dormência.

Para os dados de germinação (Tabela 2), observa-se que os tratamentos que apresentaram maior eficiência na superação da dormência, e não diferiram estatisticamente entre si, foram o tratamento de imersão por 4 dias em água destilada (T3), imersão em solução de $\mathrm{NaClO} 10 \%$ por 10 minutos e secagem e temperatura ambiente por 48 horas (T6), escarificação mecânica com lixa por 10 segundo (T11) e escarificação mecânica com lixa por 20 segundos (T12).

A embebição das sementes em água destilada por 4 dias (T3), promoveu a hidratação das sementes e amolecimento do tegumento, facilitando a protusão radicular (CARVALHO; NAKAGAWA, 2000). Já a imersão das sementes em solução de $\mathrm{NaClO} 10 \%$ por 10 minutos e secagem em temperatura ambiente por 48h (T6) ofereceu benefícios para a germinação, pois a adição de hipoclorito de sódio provoca à degradação da lignina da parede celular, removendo parcialmente a cutícula das sementes, favorecendo a superação de dormência em sementes que possuem tegumento impermeável (NOLETO et al., 2010; SOFIATT et al., 2008).

Os resultados de germinação da escarificação mecânica com lixa, por 10 ou 20 segundos, T11 e T12 respectivamente, não diferiram entre si. Segundo Medeiros Filho et al. (2002), a escarificação mecânica com lixa provoca fissuras no tegumento das sementes, aumentando à permeabilidade a água, permitindo a embebição e, consequentemente a germinação. Resultados semelhantes foram verificados para outras espécies da família Cucurbitaceae, como a Luffa cylindrica Roemer (MOREIRA et al., 2007) e Citrullus lanatus Thumb (DANTAS et al., 2003).

Esses resultados sugerem a ocorrência de dormência causada pela impermeabilidade do tegumento, pois a maior germinação ocorreu nos tratamentos que de alguma forma permitiram maior embebição. A dormência tegumentar caracteriza-se pela dificuldade de absorção de água pela semente, impedindo a hidratação e, restringindo os processos metabólicos básicos da germinação (VASCONCELLOS et al., 2010).

No entanto, quando as sementes foram submetidas à imersão em solução de $\mathrm{NaClO}$ $10 \%$ por 10 minutos e secagem em temperatura ambiente por 72 horas (T8) e, submetidas à escarificação química com $\mathrm{H}_{2} \mathrm{SO}_{4}$ concentrado por 2 minutos (T10), foram verificados os menores valores de germinação. É provável que o tempo de 72 horas de secagem após o 
tratamento com $\mathrm{NaClO} 10 \%$ por 10 minutos tenha sido prejudicial pela concentração do produto nas sementes, pois não houve lavagem após a imersão. Essa reduzida germinação observada na utilização do ácido sulfúrico concentrado pode ser explicada pelo fato do tempo de imersão ou a concentração do ácido ter prejudicado as estruturas essenciais das sementes. Conforme Rolston (1978), o ácido sulfúrico proporciona a degradação do tegumento das sementes, sendo que o aumento do período de imersão pode causar a ruptura das células, inclusive a morte das sementes.

Com relação à primeira contagem do teste de germinação (Tabela 2), os resultados foram semelhantes ao de germinação. Sendo que os maiores valores de plântulas normais vigorosas foram verificados no T3, T6, T11 e T12, da mesma forma que na porcentagem de germinação. No entanto, a menor porcentagem de plântulas normais da primeira contagem do teste de germinação foi verificada no tratamento onde as sementes foram submetidas a imersão em solução de $\mathrm{NaClO} 10 \%$ por 10 minutos e secagem em temperatura ambiente por 72 horas, assim como nos resultados de germinação.

Tabela 2. Dados médios da germinação $(\mathrm{G}, \%)$, da primeira contagem $(\mathrm{PC}, \%)$, do comprimento da parte aérea $(\mathrm{CPA}, \mathrm{cm})$, comprimento da raiz primária $(\mathrm{CR}, \mathrm{cm})$ e da massa seca (MS, g) de sementes de maxixe submetidas a tratamentos de superação da dormência ${ }^{1}$. Santa Maria, RS, 2014.

\begin{tabular}{cccccc}
\hline Tratamento & G & PC & CPA & CR & MS \\
\hline T1 & $53 \mathrm{c}$ & $27 \mathrm{~b}$ & $3,50 \mathrm{~b}$ & $3,50 \mathrm{~b}$ & $0.07 \mathrm{a}$ \\
T2 & $68 \mathrm{c}$ & $30 \mathrm{~b}$ & $0,89 \mathrm{~d}$ & $3,38 \mathrm{~b}$ & $0.07 \mathrm{a}$ \\
T3 & $97 \mathrm{a}$ & $93 \mathrm{a}$ & $4,83 \mathrm{a}$ & $5,35 \mathrm{a}$ & $0,07 \mathrm{a}$ \\
T4 & $57 \mathrm{c}$ & $20 \mathrm{~b}$ & $2,07 \mathrm{c}$ & $3,41 \mathrm{~b}$ & $0.07 \mathrm{a}$ \\
T5 & $86 \mathrm{~b}$ & $24 \mathrm{~b}$ & $3,33 \mathrm{~b}$ & $4,49 \mathrm{a}$ & $0,07 \mathrm{a}$ \\
T6 & $93 \mathrm{a}$ & $86 \mathrm{a}$ & $1,96 \mathrm{c}$ & $2,84 \mathrm{c}$ & $0.07 \mathrm{a}$ \\
T7 & $74 \mathrm{~b}$ & $18 \mathrm{~b}$ & $4,47 \mathrm{a}$ & $4,83 \mathrm{a}$ & $0,07 \mathrm{a}$ \\
T8 & $33 \mathrm{~d}$ & $2 \mathrm{c}$ & $0,05 \mathrm{e}$ & $1,13 \mathrm{~d}$ & $0,06 \mathrm{~b}$ \\
T9 & $76 \mathrm{~b}$ & $20 \mathrm{~b}$ & $2,80 \mathrm{c}$ & $2,47 \mathrm{c}$ & $0,07 \mathrm{a}$ \\
T10 & $20 \mathrm{~d}$ & $20 \mathrm{~b}$ & $2,46 \mathrm{c}$ & $1,13 \mathrm{~d}$ & $0,04 \mathrm{c}$ \\
T11 & $99 \mathrm{a}$ & $93 \mathrm{a}$ & $4,91 \mathrm{a}$ & $4,81 \mathrm{a}$ & $0,06 \mathrm{~b}$ \\
T12 & $92 \mathrm{a}$ & $78 \mathrm{a}$ & $4,89 \mathrm{a}$ & $4,65 \mathrm{a}$ & $0,06 \mathrm{~b}$ \\
\hline CV $(\%)$ & 17,90 & 17,74 & 17,18 & 17,27 & 12,61 \\
\hline
\end{tabular}

${ }^{1}$ Médias seguidas pela mesma letra na coluna não diferem entre si pelo teste de Scott-Knott, $p>0,05$.

Ainda na Tabela 2, nota-se que o comprimento da parte aérea apresentou os maiores resultados em T3, T7, T11 e T12 e o comprimento da raiz primária em T3, T5, T7, T11 e T12. Esses resultados corroboram com os de germinação e primeira contagem da germinação, mostrando que a dormência das sementes de maxixe é superada quando as sementes são submetidas aos tratamentos T3, T11 e T12. Já para o parâmetro massa seca de plântula, houve pouca variação dos resultados entre os tratamentos testados, demonstrando não ser um teste sensível para avaliação do vigor de sementes de maxixe. 
Na Tabela 3, para a emergência de plântulas em areia, não foi verificada diferença estatística entre os tratamentos para os quais esse teste foi realizado. Foram utilizados os tratamentos T3, T6 e T11 por apresentarem os melhores resultados de germinação de acordo com a metodologia proposta, ou seja, utilizando-se embebição em água destilada, imersão em $\mathrm{NaClO} 10 \%$ e escarificação mecânica. Da mesma forma que na germinação, os tratamentos apresentaram altos valores de porcentagem de emergência de plântulas em areia, mostrando serem adequados para a superação de dormência de maxixe.

Tabela 3. Dados médios da emergência (E, \%) de sementes de maxixe submetidas a tratamentos de superação da dormência. Santa Maria, RS, 2014.

\begin{tabular}{ll}
\hline Tratamento pré-germinativos & E \\
\hline T3 = Embebição por 4 dias em água destilada & $97^{\mathrm{ns}}$ \\
T6 = Imersão em NaClO 10\% por 10 minutos e secagem por & 97 \\
T11 = Escarificação mecânica com lixa por 10segundos & 93 \\
\hline CV (\%) & 6,13 \\
\hline
\end{tabular}

\section{CONCLUSÃO}

A dormência das sementes de maxixe pode ser superada com embebição por quatro dias em água destilada, imersão em solução de $\mathrm{NaClO} 10 \%$ por 10 minutos e secagem em temperatura ambiente por 48 horas e escarificação mecânica com por 10 ou 20 segundos.

\section{REFERÊNCIAS BIBLIOGRÁFICAS}

ALBUQUERQUE, K. A. D.; SILVA, P. A.; OlIVEIRA, J. A.; CARVALHO FILHO, J. L. S.; BOTELHO, F. J. E. Desenvolvimento de mudas de alface a partir de sementes armazenadas e enriquecidas com micronutrientes e reguladores de crescimento. Bioscience Journal, Uberlândia, v. 25, n. 5, p.56-65, 2009.

BRASIL. Ministério da Agricultura, Pecuária e Abastecimento - Secretaria de Defesa Agropecuária. Regras para Análise de Sementes. Brasília, DF: Mapa/ACS, 2009. 395p.

CARVALHO, N. M.; NAKAGAWA, J. Sementes: ciência, tecnologia e produção. 4. ed. Jaboticabal: FUNEP, 2000. 588 p.

DANTAS, B. F.; FERNANDES, J. G.; RIBEIRO, L. S.; ARAGÃO, C. A. Germinação de melancia armazenadas em câmara fria submetidas a tratamentos para superação da dormência. Horticultura Brasileira, Brasília, v. 21, n. 2, p.401-404, 2003.

EGLEY, G. H. Seed germination in soil: dormancy cycles. In: KIGEL, J.; GALILI, G. (ed). Seed development and germination. New York: Editora Marcel Dekker Inc. 1995. cap. 20, p. 529-543.

HAIM, N. Seed Production and Germinability of Cucurbit Crops Seed. Seed Science and Biotechnology, Japan, v. 1, n. 1, p.1-10, 2007.

Cultura Agronômica, Ilha Solteira, v.26, n.1, p.53-60, 2017 
MARCOS FILHO, J. Fisiologia de sementes de plantas cultivadas. Piracicaba: FEALQ, 2005. $495 \mathrm{p}$.

MEDEIROS FILHO, S.; FRANÇA, E. A.; INNECCO, R. Germinação de sementes de Operculina macrocarpa (L.) Farwel e Operculina alata (Ham.) Urban. Revista Brasileira de Sementes, Londrina, v. 24, n. 2, p.102-107, 2002.

MEDEIROS, M. A.; GRANGEIRO, L. C.; TORRES, S. B.; FREITAS, A. V. L. Maturação fisiológica de sementes de maxixe (Cucumis anguria L.). Revista Brasileira de Sementes, Londrina, v. 32, n. 3, p.17-24, 2010.

MOREIRA, F. J. C. INNECCO, R.; SILVA, M. A. P.; MEDEIROS FILHO, S. Tratamentos pré-germinativos em sementes de Luffa cylindrica Roemer. Revista Ciência Agronômica, Fortaleza, v. 38, n. 2, p.233-238, 2007.

NAKAGAWA, J. Testes de vigor baseados na avaliação das plântulas. In: KRZYZANOWSKI, F. C.; VIEIRA, R. D.; FRANÇA NETO, J. Vigor de sementes: conceitos e testes. Londrina: ABRATES, 1999. Cap. 2, p.1-24.

NOLETO, L. G.; PEREIRA, M. de F. R.; AMARAL, L. I. Alterações estruturais e fisiológicas em sementes de Copaifera langsdorffi Desd - Leguminosae-Caesalpinioideae submetidas ao tratamento com hipoclorito de sódio. Revista Brasileira de Sementes, Londrina, v. 32, n. 1, p.45-59, 2010.

PARREIRA, M. C.; CARDOZO, N. P.; PEREIRA, F. C. M.; AlveS, P. L. C. A. Superação de dormência das sementes e controle químico de Momordica charantia. Bioscince Jounal, Uberlândia, v. 28, n. 3, p.358-365, 2012.

QUEIRÓZ, M. A. Potencial do germoplasma de cucurbitáceas no Nordeste brasileiro. Horticultura Brasileira, Brasília, v. 11, n. 1, p.7-9, 1993.

ROLSTON, M. P. Water impermeable seed dormancy. The botanical Review, Bronx, v. 44, n. 33, p.365-396, 1978.

SOFIATTI, V.; ARAÚJO, E. F.; ARAÚJO, R. F.; REIS, M. S.; SILVA, L. V. B. D.; CARGNIN, A. Uso de hipoclorito de sódio para degradação do endocarpo de sementes de cafeeiro com diferentes graus de umidade. Revista Brasileira de Sementes, Londrina v. 30, n. 1, p.150-160, 2008.

VASCONCELLOS, J. M.; CARDOSO, T. V.; SALES, J. de F.; SILVA, F. G.;

VASCONCELOS FILHO, S. C.; SANTANA, J. da G. Métodos de superação de dormência em sementes de croada (Mourir elliptica Mart). Ciência e Agrotecnologia, Lavras, v. 34, n. 5, p.1199-1204, 2010. 